\title{
Mode of Managing Nutrient Solution Based on N Use Efficiency for Lettuce (Lactuca sativa L.)
}

\author{
Ibraimo Teleha Chabite ${ }^{1,2,3}$, Zhang Lei ${ }^{1,2}$, Yao Ningning ${ }^{1,2}$, Fu Qiang ${ }^{1,2}$ and Yu Haiye $e^{1,2}$ \\ 1. College of Biological and Agricultural Engineering, Jilin University, Changchun 130022, China \\ 2. Key Laboratory of Bionic Engineer, Ministry of Education, Jilin University, Changchun 130022, China \\ 3. Laboratory of Quality and Food Safety, University of Lúrio, Nampula 364, Mozambique
}

\begin{abstract}
In aeroponic cultivation the nutrient solution is an essential component to achieve good production results. And nitrogen is the main constituent element of the nutrient solution and essential element in plant nutrition. Therefore, the management and monitoring nutrient solution and existing nitrogen is fundamental. The experiment shows that three modes of replacing the nutrient solution and three initial pH values and their interaction significantly influenced the fresh weight and dry matter of lettuce. The highest values of fresh and dry weight were recorded in the fifth treatment where there is an interaction between $\mathrm{pH} 6$ and the mode of replacing half of the nutrient solution. The consumption rate of nitrate nitrogen $\left(\mathrm{NO}_{3}-\mathrm{N}\right)$, ammonium nitrogen $\left(\mathrm{NH}_{4}-\mathrm{N}\right)$ and gross nitrogen (GN) was higher during stage 1 (10 days after transplanting), especially for the mode of complete replacing nutrient solution.
\end{abstract}

Key words: Lettuce, aeroponic, nitrogen, nutrient solution, consumption.

\section{Introduction}

Lettuce is considered the one of most economically important leafy vegetable crops in the world [1]. According to the International Union of Soil Sciences Working Group on Soilless Culture defines aeroponics "as a system where roots are continuously or discontinuously grown in an environment saturated with fine drops (a mist or aerosol) of nutrient solution" [2]. Nutrient solution is recirculated in the aeroponics system, so a limited amount of water is used. It comparatively offers lower water and energy inputs per unit growing area [3]. Nitrogen as the nutrient supplied to plants in both negative and positive ions $\left(\mathrm{NO}_{3}{ }^{-}\right.$and $\left.\mathrm{NH}_{4}{ }^{+}\right)$forms, their external concentrations influence the uptake rates of both $\mathrm{N}$ forms. $\mathrm{NO}_{3}-\mathrm{N}$ and $\mathrm{NH}_{4}-\mathrm{N}$ are the major sources of inorganic nitrogen taken up by the roots of higher plants. However, the management of $\mathrm{NH}_{4}-\mathrm{N} / \mathrm{NO}_{3}-\mathrm{N}$ in the nutrient solution supplied to the plants, and maintaining the same total $\mathrm{N}$ concentration may considerably change the total

Corresponding author: Ibraimo Teleha Chabite, M.Sc., research field: biological agriculture. cation-to-anion uptake ratio and these changes have a profound impact on the $\mathrm{pH}$ in the root zone [4]. Agriculture has had negative impacts due to loss of natural habitat, and the misuse of pesticides and fertilizers lead to further degradation of soil and water resources to feed the world population. Besides, soilless systems have relatively small additional expense and save both fertilizers and water. Due to drain large amounts of residual nutrient solutions with high salinity for the environment has been the biggest problem for soilless plant cultivation, then recycling and reuse is a current trend of sustainable farming systems [5]. The $\mathrm{N}$ use efficiency for lettuce (Lactuca sativa L.) was researched by monitoring the concentration of $\mathrm{NH}_{4}{ }^{+}, \mathrm{NO}_{3}{ }^{-}$and gross- $\mathrm{N}$ in nutrient solution and $\mathrm{NO}_{3}^{-}$on lettuce leaves under the conditions of different management modes of replacing the nutrient solution and initial $\mathrm{pH}$ values.

\section{Materials and Methods}

\subsection{Cultivation Progress Management}

The experiment was conducted in a glass 
greenhouse at the College of biological and agricultural engineering in Jilin University (125.35 E, 43.88 N) in Changchun, Jilin Province, China. Lettuce seeds (Lactuca sativa L. var. ramosa Hort.) were allowed to germinate into small pots with $14 \mathrm{~cm}$. Plants were seeded on May 30, 2014. Twenty five days after seeding, the seedlings were transplanted into aeroponics cultivation bucket with a capacity of 10 liters and 9 plants.

Thirty days after transplanting the plants were harvested to analyze. Based on three modes of replacing the nutrient solution (Total Nutrient Solution- $\mathrm{M}_{1}$, Half of the Nutrient Solution- $\mathrm{M}_{2}$ and only Adjusting Electric Conductivity- $\mathrm{M}_{3}$ ) and three initial $\mathrm{pH}$ values (5, 6 and 7), the experiment was divided into 3 stages of production with 10-day intervals after transplanting. In certain periods during 30 days, nitratenitrogen $\left(\mathrm{NO}_{3}-\mathrm{N}\right)$, ammonium nitrogen $\left(\mathrm{NH}_{4}-\mathrm{N}\right)$ and grossnitrogen $(\mathrm{GN})$ in the nutrient solution and nitrate $\left(\mathrm{NO}_{3}{ }^{-}\right)$in lettuce leaves were measured. Then water use efficiency (WUE) and nitrogen use efficiency (NUE) were calculated. For the nutrient solution the principal elements were made up according to the Japanese Garden formula and trace elements were made up according the Hoagland General formula. In order to ensure the accuracy of the analysis, the nutrient solution was prepared by distilled water.

\subsection{Determination of N Forms in Nutrient Solution}

Every 10 days before changing $100 \mathrm{~mL}$ of the nutrient solution was collected to measure the concentration of nitrate nitrogen $\left(\mathrm{NO}_{3}-\mathrm{N}\right)$ using $\mathrm{pH}$ enoldisulfonic method, ammonium $\left(\mathrm{NH}_{4}-\mathrm{N}\right)$ using spectrophotometric method by Nessler and gross-N using persulfuric oxidation-UV spectrophotometry method.

\subsection{Determination of Leaf $N$ Content}

Thirty days after transplantation (DAT) some plants were harvested from each treatment to measure nitrate content in leaves using Salicylic Acid Colorimetric method and biomass determination. For weighing the fresh matter electronic balance was used and for dry matter in the process of drying forced-air oven was used adjusted to a temperature of $70{ }^{\circ} \mathrm{C}$, until the constant weight.

\subsection{Determination of WUE and NUE}

The following equation was used for the WUE and NUE calculation:

WUE $=$ Total yield fresh weight $/$ Total water use (g $\left.\mathrm{L}^{-1}\right)$

where Total water use $=$ was computed as the sum of cumulative water uptake and water loss.

NUE $=$ Total yield dry matter /Total nitrogen use ( $\mathrm{g}$ DM per $\mathrm{N}$ use)

where Total nitrogen use $=$ was computed from the total nitrogen content of the nutrient solutions fed to the crop (nitrogen uptake + nitrogen loss).

\subsection{Statistical Analysis}

A randomized complete design with factorial structure $(2 \times 3)$ was used. One plant was the experimental unit. Data were subjected to analysis of variance at 5\% significance level and Tukey Test was applied to parameters that showed significant differences among treatments. Also correlation coefficients were used to analyze the experimental data. All analyses were carried out using software Origin Pro 2015.

\section{Results and Discussion}

\subsection{Fresh and Dry Matter Weights}

The mean of plant fresh weight (FW) between treatments was $106.06 \pm 5.1 \mathrm{~g}$ after 4 weeks of growth. These results are lower compared with those of Albornoz et al. [1], in which obtained a mean plant fresh weight of $123.8 \pm 5.4 \mathrm{~g}$ after 3 weeks growth in the greenhouse on study to evaluate different concentrations of the nutrient solution applied during the day and night to aeroponically grown lettuce 
(Lactuca sativa L.). But our results are slightly high compared with others studies. In relation to dry matter (DM) our means were higher than those obtained by Albornozet al. [6].

In the general among the treatments, the highest FW and DM were found in $\mathrm{T}_{5}(161.48 \pm 0.3 \mathrm{~g}$ and $19.31 \pm 0.0 \mathrm{~g})$ and the lowest FW and DM in $\mathrm{T}_{2}(74.17$ $\pm 0.2 \mathrm{~g}$ and $6.14 \pm 0.0 \mathrm{~g}$ ) (Table 1 ). The means of plant FW and $\mathrm{DM}$ in $\mathrm{pH}$ values were high for $\mathrm{pH}$ 6, middle for $\mathrm{pH} 7$ and low for $\mathrm{pH}$ 5, with $123.41 \mathrm{~g} \mathrm{FW}$ and $14.3 \mathrm{~g} \mathrm{DM}, 107.8 \mathrm{~g}$ FW and $10.5 \mathrm{~g} \mathrm{DM}$, and $88.64 \mathrm{~g} \mathrm{FW}$ and $9.5 \mathrm{~g}$ DM respectively. The difference between the values of FW and DM of lettuce can be explained principally by the fact of different $\mathrm{pH}$ values, although the mode of replacing nutrient solution has its share in this difference. This shows that lettuce grows better in $\mathrm{pH} 6$ and 7 than $\mathrm{pH}$ 5. These results were agreed with many different studies. In the mode of replacing the nutrient solution the means of plant $\mathrm{FW}$ were high in $\mathrm{M}_{3}$, middle in $\mathrm{M}_{2}$ and low in $\mathrm{M}_{1}$, with $118.26 \mathrm{~g}, 116.22 \mathrm{~g}$ and $85.37 \mathrm{~g}$ respectively. The results show that the effect of nitrogen on the lettuce growth on its direct positive influence in FW and DM. In many crops the plant tissues have $\mathrm{N}$ contents ranging from $2 \%$ to $6 \%$ of the dry matter. Our experiment showed that there are significant differences $(P<0.05)$ between the three initial $\mathrm{pH}$ values and between three modes of replacing the nutrient solution, and also the interaction between those two factors is significant at level of $5 \%$ probability (Table 1).

\section{2 $\mathrm{NO}_{3}-\mathrm{N}, \mathrm{NH}_{4}-\mathrm{N}$ and $\mathrm{GN}$ Consumption Rate in the Nutrient Solution during the Cycle}

The $\mathrm{NO}_{3}-\mathrm{N}, \mathrm{NH}_{4}-\mathrm{N}$ and $\mathrm{GN}$ consumption rate for all treatments showed that there were no significant differences between the $\mathrm{pH}$ values, but there were significant differences in modes of replacing the nutrient solution at the level of $5 \%$ probability. Also, at the level of $5 \%$ probability the interaction between $\mathrm{pH}$ and the modes of replacing the nutrient solution was not significant (Table 2).

Overall the highest $\mathrm{NO}_{3}-\mathrm{N}, \mathrm{NH}_{4}-\mathrm{N}$ and GN consumption rate in the lettuce plant and its corresponding decrease in the nutrient solution were found in the first for $\mathrm{M}_{1}, \mathrm{M}_{2}$ and $\mathrm{M}_{3}$. Also the consumption rate is high in second stage for $\mathrm{M}_{1}$ and $\mathrm{M}_{2}$, having declined the consumption in stage 3 for $M_{1}$ and $M_{2}$ and in stages 2 and 3 for $M_{3}$ (Figs. 1a-1c). Although the first stage stress is not high, the nitrate is rapidly depleted in the nutrient solution, and this may be due to the preferential consumption of nitrogen and

Table 1 Varianceanalyses of FW, DM and theirinteraction at 30 days after transplanting (DAT) for lettuce grown in three initial $\mathrm{pH}$ values and three different modes of replacing the nutrient solution.

\begin{tabular}{|c|c|c|c|}
\hline & & Fresh weight (g/plant) & Dry matter (g/plant) \\
\hline \multirow{3}{*}{ pH 5} & $\mathrm{M}_{1}\left(\mathrm{~T}_{1}\right)$ & $79.04 \pm 0.1 \mathrm{~g}$ & $9.25 \pm 0.3 \mathrm{~d}$ \\
\hline & $\mathrm{M}_{2}\left(\mathrm{~T}_{2}\right)$ & $74.17 \pm 0.3 \mathrm{~h}$ & $6.14 \pm 0.0 \mathrm{f}$ \\
\hline & $\mathrm{M}_{3}\left(\mathrm{~T}_{3}\right)$ & $112.70 \pm 0.8 \mathrm{~d}$ & $13.16 \pm 0.1 \mathrm{c}$ \\
\hline \multirow{3}{*}{ pH 6} & $\mathrm{M}_{1}\left(\mathrm{~T}_{4}\right)$ & $82.04 \pm 0.1 \mathrm{f}$ & $7.34 \pm 0.1 \mathrm{e}$ \\
\hline & $\mathrm{M}_{2}\left(\mathrm{~T}_{5}\right)$ & $161.48 \pm 0.6 \mathrm{a}$ & $19.31 \pm 0.0 \mathrm{a}$ \\
\hline & $\mathrm{M}_{3}\left(\mathrm{~T}_{6}\right)$ & $126.72 \pm 0.3 b$ & $16.12 \pm 0.0 \mathrm{~b}$ \\
\hline \multirow{3}{*}{ pH 7} & $\mathrm{M}_{1}\left(\mathrm{~T}_{7}\right)$ & $95.04 \pm 0.3 \mathrm{e}$ & $9.15 \pm 0.0 \mathrm{~d}$ \\
\hline & $\mathrm{M}_{2}\left(\mathrm{~T}_{8}\right)$ & $113.00 \pm 0.0 \mathrm{~d}$ & $9.21 \pm 0.0 \mathrm{~d}$ \\
\hline & $\mathrm{M}_{3}\left(\mathrm{~T}_{9}\right)$ & $115.36 \pm 0.5 c$ & $13.02 \pm 0.0 \mathrm{c}$ \\
\hline CV (\%) & & 0.58 & 0.88 \\
\hline $\mathrm{pH}$ & & $*$ & * \\
\hline Mode & & $*$ & $*$ \\
\hline $\mathrm{pH} \times$ Mode & & $*$ & $*$ \\
\hline
\end{tabular}


Table 2 Analysis of variance for $\mathrm{NO}_{3}-\mathrm{N}, \mathrm{NH}_{4}-\mathrm{N}$ and GN consumption rate with three modes of replacing the nutrient solution, three initial $\mathrm{pH}$ values and their interaction.

\begin{tabular}{lllll}
\hline Source & $\mathrm{df}$ & $\mathrm{NO}_{3}-\mathrm{N}$ & $\mathrm{NH}_{4}-\mathrm{N}$ & $\mathrm{GN}$ \\
\hline $\mathrm{pH}$ & 2 & $\mathrm{NS}$ & $\mathrm{NS}$ & $\mathrm{NS}$ \\
Mode & 2 & $*$ & $*$ & $*$ \\
$\mathrm{pH} \times$ Mode & 4 & $\mathrm{NS}$ & $\mathrm{NS}$ & $\mathrm{NS}$ \\
\hline
\end{tabular}

NS, * Non significant and significant at $P<0.05$, respectively.

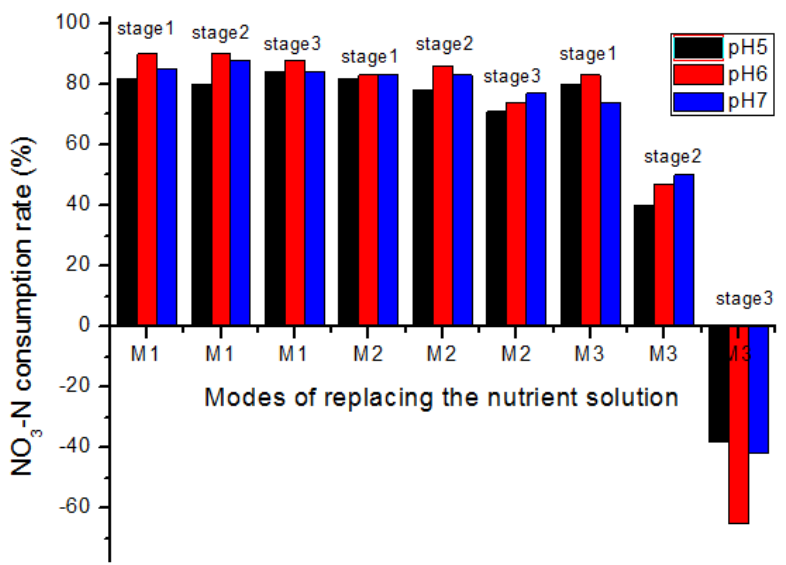

(a)

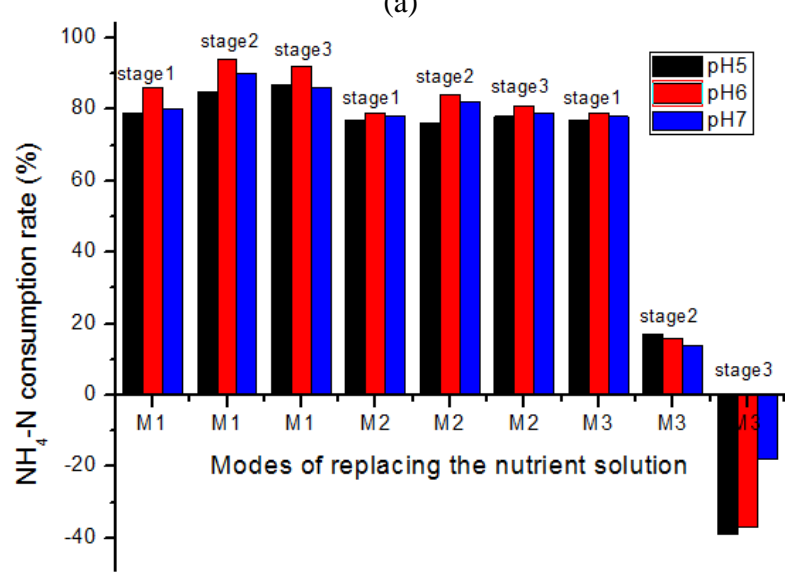

(b)

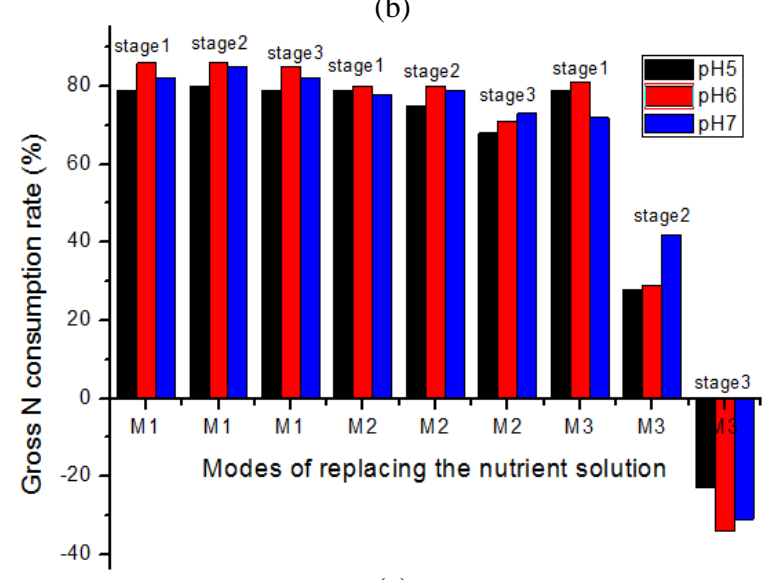

(c)

Fig. $1 \quad \mathrm{NO}_{3}-\mathrm{N}(\mathrm{a}), \mathrm{NH}_{4}-\mathrm{N}(\mathrm{b})$ and $\mathrm{GN}$ (c) consumption rate in the nutrient solution for three modes of replacing the nutrient solution and three initial $\mathrm{pH}$ values. it is known also that lettuce is regarded as a nitrate crops. Savvas et al. [4] found that $\mathrm{NH}_{4}-\mathrm{N}$ concentrations in the drainage solution dropped to nearly zero for all treatments involving the delivery of a part of the total $\mathrm{N}$ in the form of $\mathrm{NH}_{4}-\mathrm{N}$ in 23 days after planting and subsequently in the experiment with lettuce in the early spring. And Thompson et al. [7] found that the concentration variation tendencies of $\mathrm{NO}_{3}-\mathrm{N}$ and $\mathrm{NH}_{4}-\mathrm{N}$ in the nutrient solution were both similar with an initial decrease to 20 DAT followed by an increase to 20-40 DAT during the phase of rapid early growth for the two spring crops.

$\mathrm{NO}_{3}-\mathrm{N}, \mathrm{NH}_{4}-\mathrm{N}$ and $\mathrm{GN}$ consumption rate maintained high in the $\mathrm{M}_{1}$ in all stages. The reason should be nutrient supplied more sufficiently in every stage by this mode (Figs. 1a-1c), so it was more beneficial for growing. Despite these treatment with $\mathrm{M}_{1}$ have obtained the lowest fresh weight and dry matter. This shows that the uptake rates of all nutrients would be increased with increasing nutrient solution concentration although it did not contribute to increasing the yield.

In general for the $\mathrm{M}_{3}$, the lowest consumption rate was found in stage 2, and in stage 3 the consumption rate was negative. It is happening in $\mathrm{M}_{3}$ because electrical conductivity (EC) increased over time based on faster absorption of water and $\mathrm{N}$ rate for growing lettuce in stage 1 that creates an unbalance and the low availability of $\mathrm{N}$ in nutrient solution in stages 2 and 3, because in these treatments there is no replacement of nutrients on stages 2 and 3. Only water was added into nutrient solution to maintain appropriate EC for growing. So ratio of nutrient elements was always changing because never supplied. This would influence on the progress of growth and physiology of 
lettuce and nutrient absorption laws. This phenomenon of negative consumption rate appeared possibly when plants took up several chemical forms of nitrogen besides $\mathrm{NO}_{3}-\mathrm{N}$. The most common was that $\mathrm{NH}_{4}{ }^{+}$had a positive charge while $\mathrm{NO}_{3}{ }^{-}$had a negative charge, and when nitrogen forms are added to the growing medium, such as nutrient solution in aeroponics, natural processes can take place the conversion of one to another form. Hydrogen ions $\left(\mathrm{H}^{+}\right)$ which acidify the medium were released when ammonium was converted to nitrate. Plants took up ammonium and other positively charged cations by releasing one hydrogen ion $\left(\mathrm{H}^{+}\right)$into the medium solution for each ammonium ion absorbed. When nitrate uptake occurs it is usually followed by releasing hydroxide ions $\left(\mathrm{OH}^{-}\right)$and in the nutrient solution, hydroxide and hydrogen ions combine to form water $\left(\mathrm{H}_{2} \mathrm{O}\right)$. Over time the reaction of hydroxide and hydrogen ions decreased hydrogen ion concentration and increased the nutrient solution $\mathrm{pH}$. If the water uptake is continuous, certain nutrients in the solution can concentrate and be in propensity to convert to unavailable forms [8].

\subsection{Comparison and Analysis of $\mathrm{NO}_{3}{ }^{-}$in Leaves}

Nitrogen is the second most nutrient required by vegetables, limiting the lettuce production. But when
$\mathrm{N}$ absorbed exceeded the assimilation capacity this moment was observed $\mathrm{NO}_{3}{ }^{-}$accumulation in plants, then the surplus $\mathrm{N}$ inside the plant was stored as nitrate in the cell vacuoles. Nitrate accumulation in lettuce leaves can become a significant problem when grown with high $\mathrm{N}$ availability and low light, as nitrates can be converted to deleterious nitrites post-harvest [1].

Various articles show that high level of nitrate accumulation in leaves is harmful to human health [4, 6]. Overall in our experiment, the higher rate of $\mathrm{NO}_{3}{ }^{-}$ accumulation in leaves was found in all of the $\mathrm{M}_{3}$ treatments. Among them, the highest value of $\mathrm{NO}_{3}{ }^{-}$ accumulation rate was recorded in $\mathrm{T}_{3}, 3,844 \mu \mathrm{g} \mathrm{g}^{-1}$. The lowest rate of $\mathrm{NO}_{3}{ }^{-}$accumulation in the leaves was found in $\mathrm{T}_{4}, 1,216 \mu \mathrm{g} \mathrm{g}^{-1}$. All results showed that $\mathrm{pH}$ and replacing nutrient solution modes were significant influences on $\mathrm{NO}_{3}{ }^{-}$accumulation in lettuce leaves at the level of $5 \%$ probability (Table 3 ), and lower $\mathrm{pH}$ of the nutrient solution was parallel to higher $\mathrm{NO}_{3}{ }^{-}$concentration in the leaves for adjusting EC treatments. In all treatments, $\mathrm{NO}_{3}{ }^{-}$concentration of lettuce leaves (spring-summer cultivation) did not exceed limits recommended in the European Union and the World Health Organization, which were 5,000 mg. $\mathrm{kg}^{-1}$ and 4,000 mg. $\mathrm{kg}^{-1} \mathrm{FW}$ for winter and summer crops respectively for lettuce grown in greenhouse [6].

Table 3 Average values of $\mathrm{NO}_{3}{ }^{-}$content in leaves, WUE and NUE in three initial $\mathrm{pH}$ values and three different modes of replacing the nutrient solution.

\begin{tabular}{llll}
\hline Treatments & $\mathrm{NO}_{3}^{-}$content in leaves $(\mu \mathrm{g} / \mathrm{g})$ & WUE $\left(\mathrm{g} \mathrm{L}^{-1}\right)$ & NUE $(\mathrm{gDM} \mathrm{N})$ \\
\hline $\mathrm{T} 1$ & $2978 \pm 1.0 \mathrm{c}$ & $29.68 \pm 0.6 \mathrm{~h}$ & $7.84 \pm 0.0 \mathrm{~d}$ \\
$\mathrm{~T} 2$ & $2868 \pm 1.0 \mathrm{e}$ & $41.88 \pm 0.7 \mathrm{f}$ & $5.17 \pm 0.0 \mathrm{f}$ \\
$\mathrm{T} 3$ & $3844 \pm 1.0 \mathrm{a}$ & $127.80 \pm 0.7 \mathrm{c}$ & $11.12 \pm 0.1 \mathrm{c}$ \\
$\mathrm{T} 4$ & $1216 \pm 1.0 \mathrm{i}$ & $30.81 \pm 0.7 \mathrm{~h}$ & $6.75 \pm 0.1 \mathrm{e}$ \\
$\mathrm{T} 5$ & $2620 \pm 1.0 \mathrm{f}$ & $91.08 \pm 0.3 \mathrm{~d}$ & $16.53 \pm 0.4 \mathrm{a}$ \\
$\mathrm{T} 6$ & $3110 \pm 1.0 \mathrm{~b}$ & $142.91 \pm 0.7 \mathrm{a}$ & $13.82 \pm 0.2 \mathrm{~b}$ \\
$\mathrm{~T} 7$ & $2346 \pm 1.0 \mathrm{~g}$ & $35.74 \pm 0.6 \mathrm{~g}$ & $7.87 \pm 0.2 \mathrm{~d}$ \\
$\mathrm{~T} 8$ & $2021 \pm 1.0 \mathrm{~h}$ & $63.57 \pm 0.5 \mathrm{e}$ & $8.00 \pm 0.0 \mathrm{~d}$ \\
T9 & $2968 \pm 1.0 \mathrm{~d}$ & $130.19 \pm 0.4 \mathrm{~b}$ & $10.68 \pm 0.4 \mathrm{c}$ \\
$\mathrm{CV}(\%)$ & 0.23 & 0.61 & 0.01 \\
\hline
\end{tabular}

In the ANOVA values followed by the same letters in the same column are not significantly different $(P<0.05)$ according to Tukey's Test. $\mathrm{CV}=$ coefficient of variation. $\mathrm{T}_{1}=\mathrm{pH} 5+\mathrm{M}_{1} ; \mathrm{T}_{2}=\mathrm{pH} 5+\mathrm{M}_{2} ; \mathrm{T}_{3}=\mathrm{pH} 5+\mathrm{M}_{3} ; \mathrm{T}_{4}=\mathrm{pH} 6+\mathrm{M}_{1} ; \mathrm{T}_{5}=\mathrm{pH} 6+\mathrm{M}_{2} ; \mathrm{T}_{6}=$ $\mathrm{pH} 6+\mathrm{M}_{3} ; \mathrm{T}_{7}=\mathrm{pH} 7+\mathrm{M}_{1} ; \mathrm{T}_{8}=\mathrm{pH} 7+\mathrm{M}_{2} ; \mathrm{T}_{9}=\mathrm{pH} 7+\mathrm{M}_{3}$. 
The $\mathrm{NO}_{3}^{-}$accumulation in lettuce leaves has negative relationship $\left(\mathrm{R}^{2}=0.52 ; P<0.05\right)$ with the GN consumption (Fig. 2a) and $\mathrm{NO}_{3}-\mathrm{N}$ consumption $\left(\mathrm{R}^{2}=0.51 ; P<0.05\right)$ in the nutrient solution (Fig. 2b). Many studies had shown a negative relationship between $\mathrm{NO}_{3}-\mathrm{N}$ uptake rateand $\mathrm{NO}_{3}{ }^{-}$accumulation in plants. This obviously reflected a complex mechanism of $\mathrm{NO}_{3}-\mathrm{N}$ uptake and transformation. Fig. 2c showed that there was a significantly positive correlation $\left(\mathrm{R}^{2}=\right.$ 0.90686; $P<0.05$ ) between the $\mathrm{NO}_{3}-\mathrm{N}$ consumption rate and the FW of the lettuce. This was a reason why growers tended to apply more even overmuch nitrogen fertilizer to vegetables.

3.4 Water Use Efficiency (WUE) and Nitrogen Use Efficiency (NUE)

WUE is one of the functional indicators strongly related to plant growth and health under water deficit condition, it is dependent on the amount of water usedfor growth and biomass production [9]. The experiment showed that WUE is higher in treatments where we find the $M_{3}$. In these treatments is used the same nutrient solution over the three stages of cultivation. This shows that how much less is the amount of nutrient solution used to supply the higher will be the WUE. Many previous studies have observed that WUE was improved under water limitation [9]. The effects of the three modes of replacing the nutrient solution and three initial $\mathrm{pH}$ values and their interaction on the WUE of the lettuce plant were significant (Table 3). The highest WUE value $\left(142.91 \pm 0.7 \mathrm{~g} \mathrm{~L}^{-1}\right)$ was measured in the $\mathrm{M}_{3}$ with $\mathrm{pH} 6\left(\mathrm{~T}_{6}\right)$ and lowest value $\left(29.68 \pm 0.6 \mathrm{~g} \mathrm{~L}^{-1}\right)$ was found in $\mathrm{M}_{1}$ with $\mathrm{pH} 5\left(\mathrm{~T}_{1}\right)$. This shows that minimizing the water discharge in aeroponics systems increases the WUE considerably. AlKhader and Rayyan [10] found highest WUE for the lettuce head plant $1.87 \mathrm{~g} / \mathrm{mm}$ and lowest value $0.17 \mathrm{~g} / \mathrm{mm}$.

The NUE of crops can be improved via bioengineering or management strategies [11]. The appropriate way to estimate NUE eventually depends

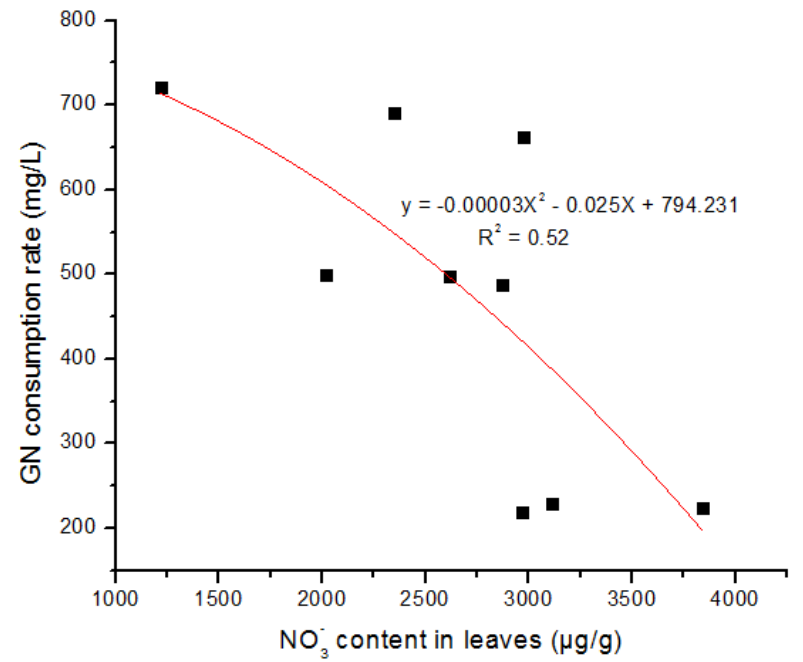

(a)

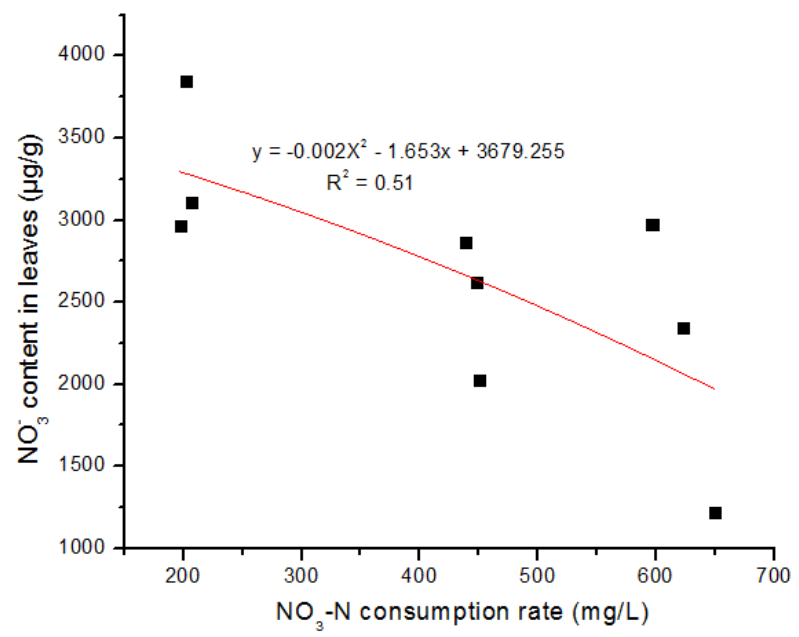

(b)

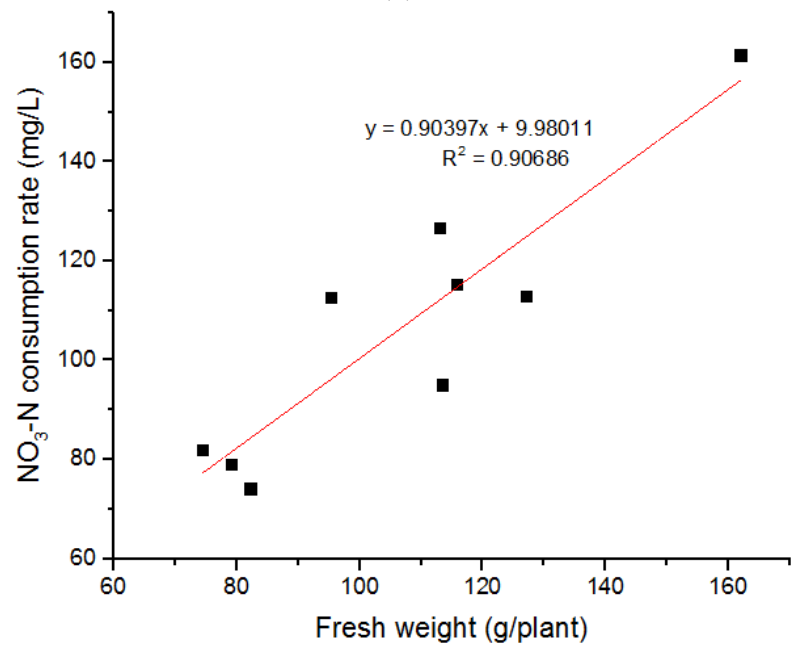

(c)

Fig. 2 Relationship between $\mathrm{NO}_{3}{ }^{-}$accumulation in lettuce leaves with gross $\mathrm{N}$ consumption (a) and $\mathrm{NO}_{3}{ }^{-} \mathrm{N}$ consumption in the nutrient solution (b) and relationship between $\mathrm{NO}_{3}-\mathrm{N}$ consumption rate and $\mathrm{FW}(\mathrm{c})$. 
on the crop, its harvest product, and specific physiological processes involved in NUE [12]. The three modes of replacing the nutrient solution and three initial $\mathrm{pH}$ values influenced significantly NUE (Table 3) and the most efficient treatment $\left(\mathrm{T}_{5}\right)$ was found in the $\mathrm{M}_{2}$ with $\mathrm{pH} 6$ (16.53 $\pm 0.4 \mathrm{~g}$ Dmper Nuse). Dai et al. [13] found NUE ranged from 16.37 to $20.46 \mathrm{~kg} \mathrm{~kg}^{-1}$ in winter wheat. A field research in the United Kingdom for different crops production indicated that sugar beet has the highest NUE with 69 (kilograms DM per Navailable), followed by potato with 40 (kilograms DM per Navailable); oilseeds and peas have the lowest NUE, at 9 and 6 (kilograms DM per Navailable), respectively [11].

In aeroponics vegetable production, optimizing nitrogen and water use efficiency is very important, in order to secure the $\mathrm{N}$ and Water efficient supply for thecrops and to protect the environment. Carbon, nitrogen and water uptakes rates are the key processes determining fresh yield of vegetables [5]. Improved water use efficiency (WUE) representsa key factor in increasing crop productivity under suchwater scarcity conditions [10], and improving NUE might help to limit use of $\mathrm{N}$ fertilizers and to preserve the environment and public health [14]. The efficiency of WUE and NUE changed significantly among treatments. The experiment shows that there is positive correlation between WUE and NUE with FW and DM (Figs. 3a and 3b). This relationship shows that the fresh weight is the factor that most influences the WUE variations and DM is the main factor explaining NUE variations whatever the $\mathrm{N}$ or water supply. Chardon et al. [14] found also that NUE was positively correlated with DM and FM in the study of Natural variation of nitrate uptake in Arabidopsis. Fig. 3c shows that there is a negative correlation between nitrogen uptake $(\mathrm{Nu})$ with WUE $\left(\mathrm{R}^{2}=0.88 ; P<0.05\right)$ and NUE $\left(\mathrm{R}^{2}=0.26 ; P<0.05\right)$. This shows that when there is a higher nitrogen uptake $(\mathrm{Nu})$ in the plant causes the decrease of the nitrogen and water use efficiency. These results are in agreement with
Gholamhoseini et al. [15], which reported that NUE decreased in high frequency and low irrigation regime with enhancement of $\mathrm{N}$ application. Studies in the last

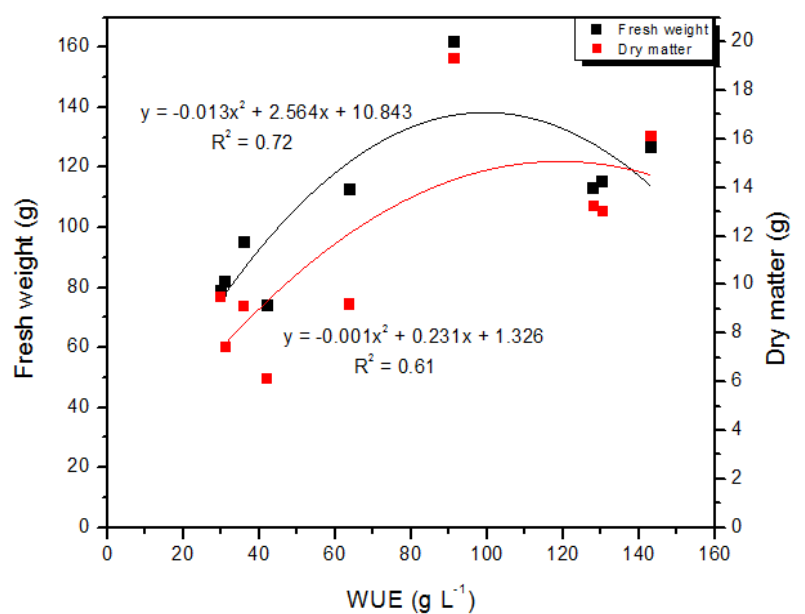

(a)

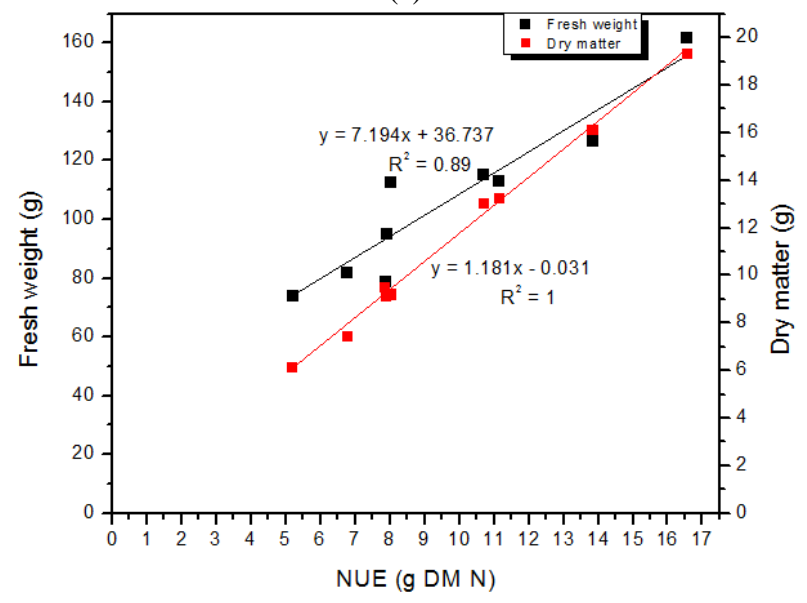

(b)

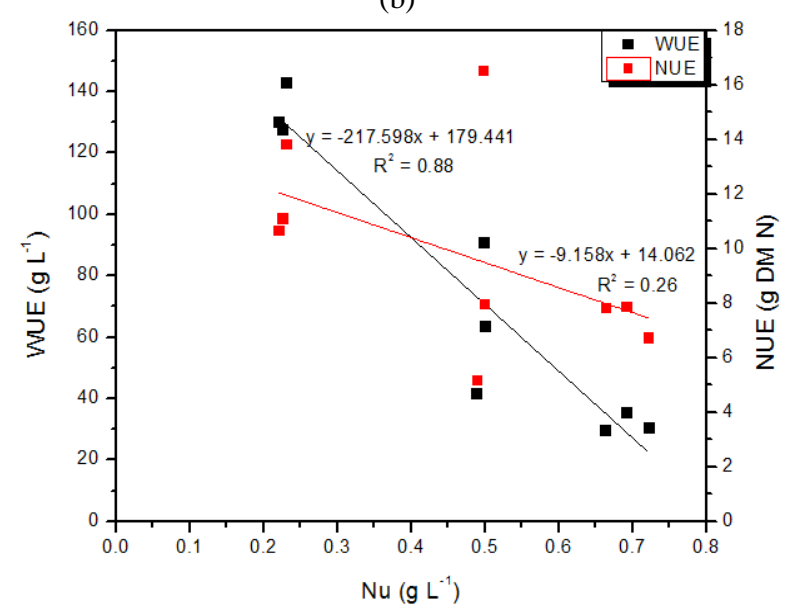

(c)

Fig. 3 Relationship between WUE with FW and DM (a), NUE with FW and DM (b) and Nu with WUE and NUE (c) for nine experimental treatments. 
decade have shown that enhancing the up take of $\mathrm{N}$ by over expressing transporters may not necessarily improve NUE [12]. The results in Table 3 underscore this principle by showing that both WUE and NUE the highest means were recorded in treatments which used the same nutrient solution throughout the entire cycle, $\mathrm{M}_{3}$. Point out that one of the conditions which renders the availability of nutrients in the soil or in nutrient solutions for roots absorption is necessary that there is a sufficient amount of water to dissolve the nutrients existing in it.

\section{Conclusion}

In this experiment it was found that two factors (mode of replacing the nutrient solution and $\mathrm{pH}$ values) and their interaction significantly influenced the fresh weight, dry matter, $\mathrm{NO}_{3}{ }^{-}$concentration in the leaves, WUE and NUE. We conclude that aeroponics lettuce can grow well in half nutrient solution $\mathrm{M}_{2}$ with $\mathrm{pH} 6$ and when keeping the same nutrient solution without replacement or exchange for a longer period there is a trend for nitrate accumulation in the leaves.

In aeroponics WUE and NUE can be improved to some extent by optimizing fertilizer and water interactions managing the nutrient solution. The most efficient treatments in WUE and NUE were all that used the same nutrient solution in all cycle, $\mathrm{M}_{3}$.

\section{Acknowledgment}

The publication of this manuscript was supported by the Fogarty International Center of the National Institutes of Health (Office of the Director, National Institutes of Health), Eunice Kennedy Shriver National Institute of Child Health \& Human Development (NICHD) National Institute of Neurological Disorders and Stroke (NINDS) under Award Number D43TW010135.

The content is solely the responsibility of the authors and does not necessarily represent the official views of the National Institutes of Health.

\section{References}

[1] Stefanelli, D., Winkler, S., and Jones, R. 2011. "Reduced Nitrogen Availability during Growth Improves Quality in Red Oak Lettuce Leaves by Minimizing Nitrate Content, and Increasing Antioxidant Capacity and Leaf Mineral Content.” Agricultural Sciences 4 (2): 477-86.

[2] Maroya, N. G., Balogun, M., and Asiedu, R. 2014. "Seed Yam Production in an Aeroponics System: A Novel Technology.” YIIFSWA Working Paper, Series No. 2.

[3] Chiipanthenga, M., Maliro, M.,Demo, P., and Njoloma, J. 2012. "Potential of Aeroponics System in the Production of Quality Potato (SolanumTuberosum L.) Seed in Developing Countries.” African Journal of Biotechnology 11 (17): 3993-9.

[4] Savvas, D., Passam, H. C., and Olympios, C. 2006. "Effects of Ammonium Nitrogen on Lettuce Grown on Pumice in a Closed Hydroponics System.” HortScience 41 (7): 1667-73.

[5] Andriolo, J. L., Godoi, R. S.,Cogo, C. M., Bortolotto, O. C., Luz, G. L., and Madaloz, J. C. 2006. "Growth and Development of Lettuce Plants at High NH4:NO3-Ratios in the Nutrient Solution.” Horticultura Brasileira 24: 352-5.

[6] Albornoz, F., Lieth, J. H., and González-Fuentes, J. A. 2014. "Effect of Different Day and Night Nutrient Solution Concentrations on Growth, Photosynthesis, and Leaf $\mathrm{NO}_{3}^{-}$Content of Aeroponically Grown Lettuce.” Chilean Journalof Agricultural Research74 (2): 240-5.

[7] Thompson, R. B., Gallardo, M., Rodríguez, J. S., Sánchez, J. A., and Magán, J. J. 2013. "Effect of N Uptake Concentration on Nitrate Leaching from Tomato Grown in Free-Draining Soilless Culture under Mediterranean Conditions.” Scientia Horticulturae 150: 387-98.

[8] Mattson, N., Leatherwood, R., and Peters, C. 2009. "Nitrogen: All Forms Are Not Equal." GMPro. Magazine.

[9] Rahimi, A., Sayadi, F., Dashti, H., and A. Pour, A. T. 2013. "Effects of Water and Nitrogen Supply on Growth, Water-Use Efficiency and Mucilage Yield of Isabgol (Plantago Ovata Forsk).” Journal of Soil Science and Plant Nutrition 13 (2): 341-54.

[10] AlKhader, and Rayyan, A. 2013. "Improving Water UseEfficiency of Lettuce (Lactuca sativa L.) Using Phosphorous Fertilizers.” SpringerPlus 2:563.

[11] MacDonald, W. N., Blom, T. J., Tsujita, M. J., and Shelp, B. J. 2013. "Review: Improving Nitrogen Use Efficiency of Potted Chrysanthemum: Strategies and Benefits.” Can. J. Plant Sci. 93: 1009-16.

[12] Pathak, R. R., Lochab, S., and Raghuram, N. 2011. "Plant Systems-Improving Plant Nitrogen-Use Efficiency.” In Comprehensive Biotechnology, 2nd ed., Vol. 4, edited by 
Moo-Young, M. Elsevier: 209-18.

[13] Dai, X., Zhou, X., Jia, D., Xiao, L., Kong, H., and He, M. 2013. "Managing the Seeding Rate to Improve Nitrogen-Use Efficiency of Winter Wheat.” Field Crops Research 154: 100-9.

[14] Chardon, F., Barthélémy, J., Daniel-Vedele, F., and Masclaux-Daubresse, C. 2010. "Natural Variation of Nitrate Uptake and Nitrogen Use Efficiency in Arabidopsis
Thaliana Cultivated with Limiting and Ample Nitrogen Supply.” Journal of Experimental Botany 61 (9): 2293-302.

[15] Gholamhoseini, M., Alikhani, M. A., Sanavy, S. A. M., and Mirlatifi, S. M. 2013. "Interactions of Irrigation, Weed and Nitrogen on Corn Yield, Nitrogen Use Efficiency and Nitrate Leaching." Agricultural Water Management 126: 9-18. 